\title{
ISOLATED TESTICULAR TUBERCULOSIS: A DUBIOUS FACADE
}

\section{Darwin Britto Devadhason' ${ }^{1}$, Alankrith Ramesh Kashyap², Arun Prasanth³, Mohamed Musthafa4, Kalaivani Amitkumar ${ }^{5}$}

${ }^{1}$ Assistant Professor, Department of General Surgery, SRM Medical College, Hospital \& Research Centre, Chennai.

${ }^{2}$ Postgraduate, Department of General Surgery, SRM Medical College, Hospital \& Research Centre, Chennai.

3Postgraduate, Department of General Surgery, SRM Medical College, Hospital \& Research Centre, Chennai.

4 Professor, Department of General Surgery, SRM Medical College, Hospital \& Research Centre, Chennai.

${ }_{5}^{5}$ Associate Professor, Department of Pathology, SRM Medical College, Hospital \& Research Centre, Chennai.

\section{ABSTRACT}

\section{BACKGROUND}

Isolated testicular tuberculosis is a bizarre entity and it can present with atypical clinical features and its radiological signs remain elusive. Owing to its unusual occurrence and presentation, it can be confused with testicular tumour as has been presented in this case of a 54-year-old male patient who presented with absolutely no clinical symptoms other than a painless progressive left scrotal swelling.

\section{KEYWORDS}

Testicular Tuberculosis, Caseous Necrosis, Testicular Tumour.

HOW TO CITE THIS ARTICLE: Devadhason DB, Kashyap AR, Prasanth A, et al. Isolated testicular tuberculosis: a dubious facade. J. Evolution Med. Dent. Sci. 2016;5(69):5045-5046, DOI: 10.14260/jemds/2016/1145

\section{INTRODUCTION}

Genitourinary tuberculosis accounts for $30 \%$ of extrapulmonary tuberculosis with testis being rarely involved; a result of extension from infected epididymis which clinically masquerades a testicular tumour.[1,2] Formation of tubercles occurs within the seminiferous tubules and connective tissue of the testis, leading to caseous necrosis and fibrosis.[1]

\section{CASE REPORT}

A 54-year-old male came with complaints of painless, progressive swelling in left scrotum since past 6 months. There was no history of trauma, discharge from the swelling, fever, cough with expectoration, loss of weight. There was no history of burning urination or infertility. He was a known Diabetic on regular medication. He had no other co-morbidities nor was he a smoker/alcoholic. There was no history of chronic drug intake/previous surgery. Examination revealed swelling in left scrotum, not warm, not tender and hard in consistency with left testis not separately palpable, not transluminant and can get above the swelling. Skin over the swelling normal with no regional lymphadenopathy. A clinical diagnosis of hydrocele with suspicious left testicular tumour was made.

Ultrasonogram Scrotum: Left testis showing variable echogenicity, left > right hydrocele and prostatomegaly.

Computed Tomography (CT) Abdomen: Simple cyst in segment VIII of liver. No inguinal lymphadenopathy.

Magnetic Resonance Imaging (MRI) Pelvis: Hypointense lesion in left testis measuring $1.4 \times 1.5 \times 1.3 \mathrm{~cm}$ within posteromedial aspect of left testis - likely neoplastic lesion, bilateral hydrocele.

Financial or Other, Competing Interest: None

Submission 23-07-2016, Peer Review 17-08-2016,

Acceptance 22-08-2016, Published 29-08-2016.

Corresponding Author:

Dr. Alankrith Ramesh Kashyap,

Room 303, PG Medical Gents Hostel,

SRM College Hospital \& Research Centre,

SRM Nagar, Kattankulathur,

Chennai-603203.

E-mail: koolchant@gmail.com

DOI: $10.14260 /$ jemds/2016/1145

\section{Chest X-Ray}

Normal.

Serum Alpha-Fetoprotein (AFP)

$2.85 \mathrm{ng} / \mathrm{mL}$ (Normal $<10 \mathrm{ng} / \mathrm{mL}$ )

Serum Beta-HCG

$<0.1 \mathrm{mIU} / \mathrm{mL}$ (Normal: $0-5 \mathrm{mIU} / \mathrm{mL}$ )

\section{Serum LDH}

177 U/L (Normal: 140-280 U/L)

Total Count

7,500 cells/cu.mm (Normal: 4000-11000 cells/cu.mm)

A diagnosis of testicular tumour was made and patient was planned high orchidectomy under ASA Physical Status GradeII. Left testis with cord sent for histopathological examination (Figure 1).

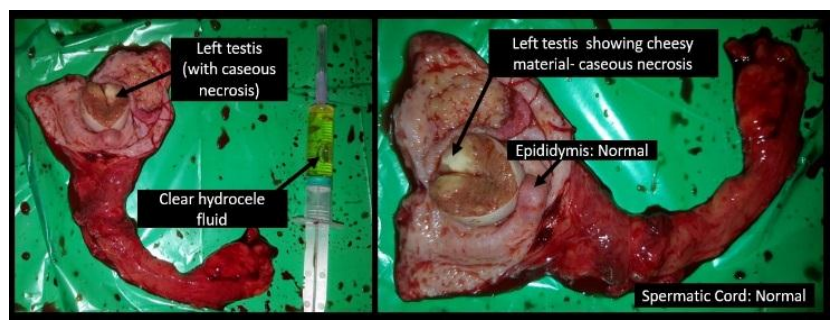

Fig. 1: Cut Section of Left Testis shows Unifocal Relatively Circumscribed Gray-White Homogeneous Nodular Lesion with Cheesy White Soft Areas (Caseous Necrosis) and Clear Hydrocele Fluid. The Epididymis and Rest of the Cord are Normal.

On gross examination of cut specimen testicular tuberculosis was suspected, hence sputum for Acid Fast Bacilli (AFB) and Serum Adenosine Deaminase (ADA) was sent while the histopathology report was awaited.

Sputum AFB

Negative. 


\section{Serum ADA}

8.2 $\mathrm{U} / \mathrm{L}$ (ADA value $>100 \mathrm{U} / \mathrm{L}$ is highly suggestive of tuberculosis).

\section{Hydrocele Fluid Cytology}

Negative for malignant cells.

\section{Histopathology Report}

Testicular parenchyma is mostly replaced by caseous necrosis and well-defined and confluent epithelioid granulomas admixed with foamy macrophages and occasional Langhans type giant cells. Adjacent testicular parenchyma shows features of atrophy.

Epididymis, rete testis, spermatic cord and tunica vaginalis are free of tuberculous involvement (Figure 2).

\section{Histochemistry}

Acid fast staining showed occasional bacilli. Fite Faraco and PAS were negative.
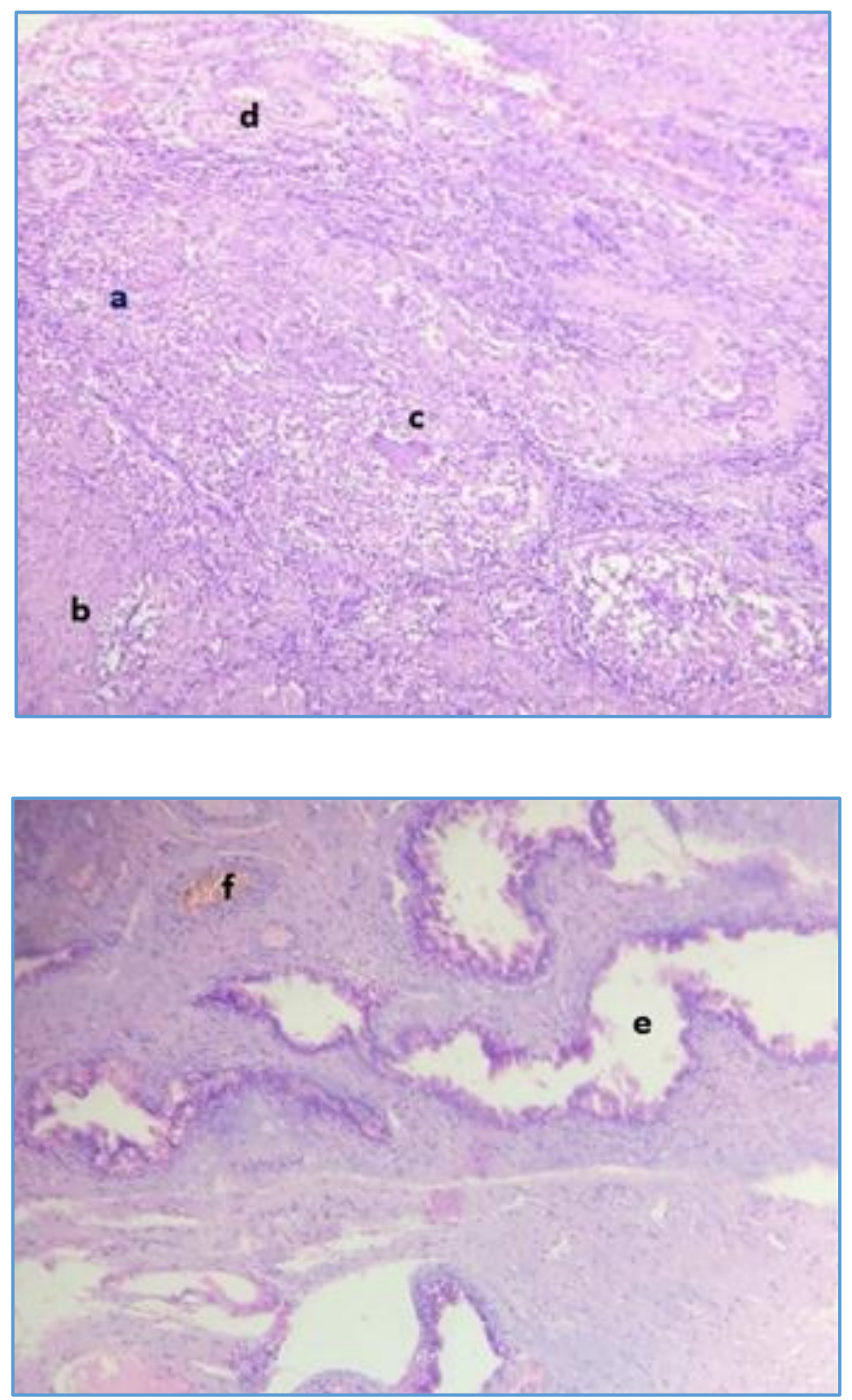

Fig. 2: Section from Testis shows Epithelioid Granulomas (a) with Caseous Necrosis (b) and Langhans Giant Cells (c). Top Left Corner shows Atrophied Seminiferous Tubules (d); Section from Epididymis shows Unremarkable Histological Features, Absence of Tuberculous Focus in Epididymal Ducts (e) and Blood Vessels (f). H\&E, 440
Patient was started on Anti-Tubercular Therapy (ATT) and discharged.

\section{DISCUSSION}

The incidence of isolated genitourinary tuberculosis is very rare $4 \%$ and solitary involvement of testis without epididymis involvement is almost negligible $\sim 1.6 \%$ among genitourinary tuberculosis, as infection of testis occurs due to local invasion of epididymis, retrograde spread from epididymis and rarely haematogenous route.[3,4,5,6,7] Testicular tuberculosis usually affects ages from 30-50 years, but it creates a diagnostic impasse when it presents as a painless, diffuse testicular swelling in absence of fever, burning urination or infertility and clinical examination revealing non-tender indurated testis thus mimicking a testicular neoplasm. ${ }^{[5,6,7,8]}$ Testicular neoplasms are hypoechoic on Ultrasonogram and show hypointense enhancement on T1W MRI images.[5] As the findings of Ultrasonogram are non-significant and the rarity in incidence of isolated testicular tuberculosis; any testicular swelling presenting with atypical features should be treated as testicular tumour (with orchidectomy) unless proven otherwise.[5] Histopathology confirms the diagnosis of testicular tuberculosis by presence of granulomas consisting of caseous necrosis, plasma cell infiltration, epithelioid cells, Langhans Giant cells and ATT should be started.[8]

\section{CONCLUSION}

The case presented here puts the surgeon in diagnostic and therapeutic perplexity due to, 1) Painless diffuse swelling without other features of any bacterial infection, 2) Ultrasonogram being non-specific and MRI pelvis showing features of testicular neoplasm, 3) Chest X-ray being completely normal, 4) Sputum AFB and serum ADA were normal. This dubious facade shows the misfortune of such patients who have to face the tribulation of having to undergo an orchidectomy, and isolated tuberculosis of testis being an incongruent entity needs a thorough research for its early and prompt diagnosis in the near future.

\section{REFERENCES}

1. Wein AJ, Kavoussi LR, Novick AC, et al. Campbell-Walsh Urology. $10^{\text {th }}$ ed. Philadelphia PA: Elsevier Saunders 2012:468-70.

2. Tuberculosis: clinical diagnosis and management of tuberculosis, and measures for its prevention and control. Royal College of Physicians 2006:35.

3. Schaaf SH, Zumla AI, Grange J, et al. Tuberculosis: a comprehensive clinical reference. London: WB Saunders Elsevier 2009.

4. Das P, Ahuja A, Gupta SD. Incidence, aetiopathogenesis and pathological aspects of genitourinary tuberculosis in India: a journey revisited. Indian J Urol 2008;24(3): 356-61.

5. Bakir S, Isen K. Isolated testicular tuberculosis mimicking a testicular tumor. Ege Journal of Medicine 2010; 49(1):59-62.

6. Chakrabarti I, Das V, Ghosh N. Isolated testicular tuberculosis masquerading as a testicular tumor. J Microbiol Infect Dis 2015;5(2):76-8.

7. Biswas M, Rahi R, Tiwary SK, et al. Isolated tuberculosis of testis. Kathmandu University Medical Journal 2006; 4(1):98-9.

8. Shenoy VP, Viswanath S, D'Souza A, et al. Isolated tuberculous epididymo-orchitis: an unusual presentation of tuberculosis. J Infect Dev Ctries 2012;6(1):92-4. 